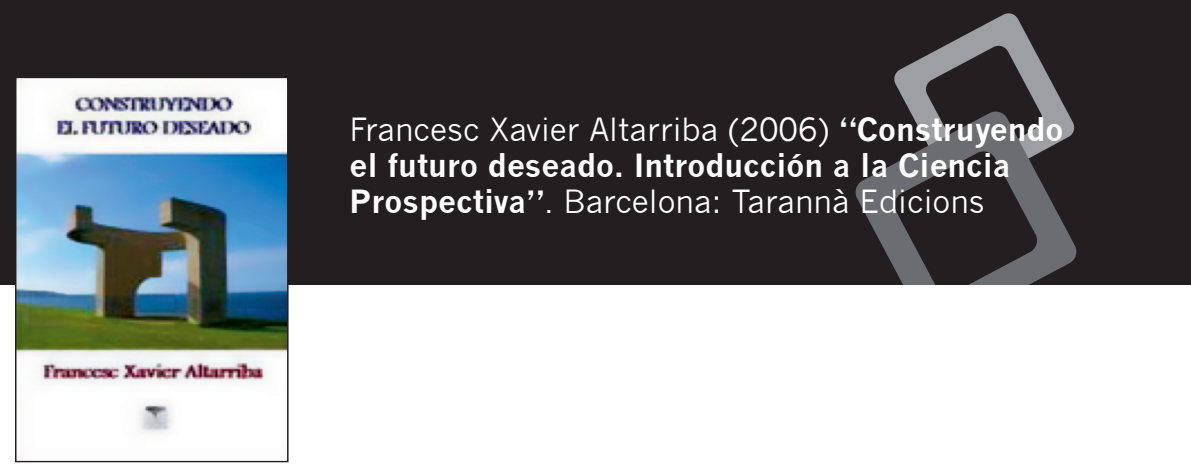

\title{
Construyendo el futuro deseado. Introducción a la Ciencia Prospectiva
}

El autor Francesc Xavier Altarriba introduce al lector a la Ciencia Prospectiva a través de la presentación de conceptos claves como pasado, presente y futuro, consciencia y conciencia, crisis y cambios, azar y posibilidad, por mencionar algunos; expone las técnicas de la Prospectiva, sus métodos y aplicaciones; presenta además una síntesis en la que incluye ejemplos, casos prácticos y reflexiones operativas en relación a la misma.

Se define la Prospectiva como la ciencia aplicada, interdisciplinar, orientada a detectar, conocer y diferenciar las variables que condicionan o determinan, tanto el marco como la evolución de los componentes que configuran el futuro, influyendo sobre ellos, para facilitar la emergencia de los escenarios posibles y los parámetros más favorables, en base a unos criterios electivos predeterminados, para influir en la generación y desarrollo del contexto más idóneo. La prospectiva brinda un instrumento objetivo, controlable y con capacidad de aprehenderlo para hacer conocido y próximo, lo desconocido y remoto.

La Ciencia Prospectiva pretende dar respuesta a lo que va ser el futuro, considerándolo como una mezcla de circunstancias externas, condicionamientos y voluntades reivindicativas; se estructura mediante el método científico de objetividad, replicabilidad y contrastación, diferenciando argumentos y criterios de opiniones y posiciones ideológicas. Su único fin es objetivar y considerar las posibilidades de futuro y trabajar para hacer probable el elegido, u optimizar sus posibilidades de convertirse en realidad, reduciendo incertidumbres y favoreciendo certezas.

Entre las técnicas necesarias para conocer qué es y cómo actúa esta ciencia, el autor establece el método de los escenarios, cuyo principal objetivo es generar una base técnicamente construida para pautar y rentabilizar el abordaje objetivo frente al análisis de situaciones con posibilidades de futuro; el Análisis Estructural y el método MICMAC, su objetivo se manifiesta en las relaciones legítimas entre las variables cualitativas y cuantitativas; el método MACTOR, basado en el análisis del rol de los actores de un sistema; el análisis morfológico, que constituye un instrumento basado en la fragmentación de un sistema con el objetivo de reducir la incertidumbre, para ello utiliza el método Delphi, Cross-impact, SMIC y Prob-Expert. 


\section{LIBROS}

Otros métodos planteados por el autor incluyen el diagnóstico prospectivoestratégico, que implica una simbiosis entre la anticipación del conocimiento de la realidad factible, aprehensión objetivo-causal de la misma, valoración de efectos, influencia de factores condicionantes, jerarquizar por orden posibilidadprobabilidad, elección de la acción y evaluación contrastada de la realidad. Además el método de decantación de opciones, criterios múltiples, Electra II, Multipol y los árboles de decisiones.

Se establecen tres tipologías de Prospectiva: La tipología Predictiva, cuya razón de ser es prever con precisión para actuar con eficacia; la Prospectiva de Pronóstico, que configura y analiza los escenarios futuribles, valora la praxis y la aplicabilidad e incorpora relaciones de base lineal; y la Prospectiva Crítica, que se fundamenta en la creatividad, potencia la opción de libertad como base para decidir mejor el futuro, sin proyectar necesariamente el presente.

El autor culmina con la presentación de los escenarios en los cuales intuye que se desarrollará la visión prospectivista, entre ellos destaca la incorporación a las decisiones políticas mediante la priorización de alternativas de contenido ideológico y de gestión para minimizar el riesgo y maximizar la rentabilidad electoral; en las decisiones empresariales; en el mantenimiento y optimización en el ámbito de la defensa, en el cual incluye a los cuerpos policiales, que se ven beneficiados de los avances en prospectiva gracias a su método anticipador de conflictos y delitos; las Organizaciones No Gubernamentales, las universidades, las administraciones públicas, las creencias y los estilos de vida, también se presentan como ámbitos de desarrollo para la Ciencia Prospectiva.

El libro resulta relevante en tanto que constituye una guía para la implementación de las técnicas y métodos adecuados que permitan reducir las incertidumbres y que el ser humano defina con cierto grado de certeza el futuro, por ser este sujeto, objeto y gestor de su propia historia.

Sinopsis a cargo de Alejandra Patricia Gutiérrez Portillo Unidad de Acceso a la Información Pública Institucional (UAIPI-ANSP) 